\title{
EL HUEVO EN LOS ANTIGUOS ALQUIMISTAS GRIEGOS: UN ACERCAMIENTO AL ORIGEN DEL CONCEPTO «HUEVO FILOSÓFICO»
}

\author{
Aurelio J. Fernández García \\ IES Viera y Clavijo \\ afergar@gmail.com
}

\section{RESUMEN}

Hay numerosos materiales y sustancias que los antiguos alquimistas empleaban como su «materia prima». Uno de estos es el huevo -las partes de un huevo-, que presenta una significación emblemática o simbólica desde los primeros textos alquímicos griegos. En este sentido, caben

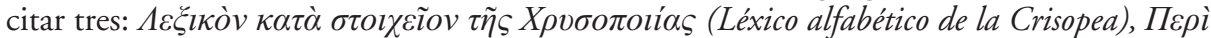

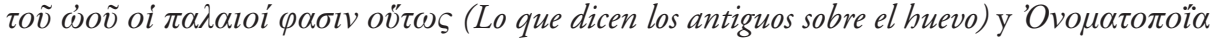

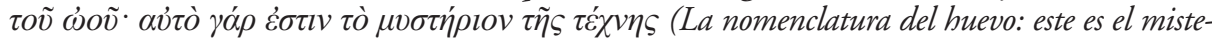
rio del arte). En estos textos, de los que se ofrece en este trabajo, además del texto griego, una traducción, se encierra toda una nomenclatura alegórica, desconocida para los no iniciados en la alquimia.

En la última parte de este trabajo, se comentará un posible origen del concepto de «huevo filosófico», a partir de uno de los pasajes del texto La nomenclatura del huevo: este es el misterio del arte.

PALABRAS ClaVE: Huevo, yema, clara, cáscara, alquimia, huevo filosófico.

THE EGG IN THE ANCIENT GREEK ALCHEMISTS:

AN APPROACH TO THE ORIGIN OF THE CONCEPT OF «PHILOSOPHICAL EGG»

\section{ABSTRACT}

There are numerous materials and substances that the ancient alchemists used as their raw material. One of these is the egg, which has an emblematic or symbolic significance since the first Greek alchemical texts. In this sense, it is worth mention three: $1 \varepsilon \xi \xi \kappa o ̀ v ~ \kappa \alpha \tau \dot{\alpha} \sigma \tau o l \chi \varepsilon i ̃ o v$

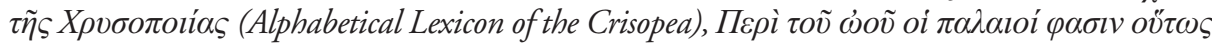

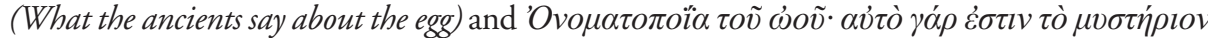
$\tau \tilde{\eta} \varsigma \tau \dot{\varepsilon} \chi v \eta \varsigma$ (The nomenclature of the egg: this is the mystery of art). In these texts, of which a translation is offered in this work, in addition to the Greek text, a whole allegorical nomenclature is enclosed, unknown to the uninitiated in alchemy.

In the last part of this work, a possible origin of the concept of "philosophical egg" will be discussed, based on one of the passages in the text The nomenclature of the egg: this is the mystery of art.

KEYwORDs: Egg, yolk, egg white, shell, alchemy, philosophical egg. 
Los textos de los manuscritos alquímicos griegos ${ }^{1}$ presentan numerosos problemas de interpretación por el variado y confuso simbolismo que se recoge en ellos ${ }^{2}$, así como por la complejidad y la incomprensibilidad de las operaciones alquímicas que describen.

La adecuada interpretación de los conceptos, las representaciones, los símbolos y los mensajes en clave que contienen las operaciones alquímicas estaba en manos de personas especialistas que eran capaces de conocer y descifrar sus códigos y propiedades internas: los alquimistas ${ }^{3}$. Para ello, estos debían contar, en primer lugar, con la "materia prima» -uno de los misterios o secretos más celosamente guardados por los alquimistas ${ }^{4}$, es decir, con los materiales o las sustancias (minerales, vegetales, líquidos...) precisos y de tal manera proporcionados, para que en su mezcla se mariden los dos principios básicos de la naturaleza (positivo y negativo o masculino y femenino), necesarios para su lenta transformación; en segundo lugar, con el correcto instrumental técnico (hornos, recipientes, vasos...) $)^{5}$ para trabajar dichos materiales o sustancias; y, en tercer lugar, con el lugar específico de operación para los cambios de estado de esa "materia prima»: el laboratorio alquímico.

El huevo juega un papel capital desde los orígenes de la alquimia griega y constituye uno de sus componentes y símbolos más representativos, que adquiere a lo largo de la historia múltiples y variadas interpretaciones. De esta forma, en este trabajo, se van a dar a conocer tres textos griegos de alquimia, en los que el huevo o sus partes conforman la "materia prima» para realizar una operación alquímica. Posteriormente y a partir de un pasaje de uno de los textos presentados, se hablará de lo que se denomina el «huevo filosófico».

En efecto, el huevo -las partes de un huevo- como «materia prima» tiene una significación emblemática o simbólica y aparece citado desde los primeros textos

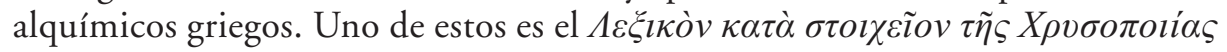

${ }^{1}$ Los principales manuscritos alquímicos griegos son el Marcianus graecus 299 (= M), el Parisinus graecus 2325 (= B), el Parisinus graecus 2327 (= A) y el Laurentianus graecus 86, 16 (= L). Un desarrollo de sus contenidos se puede ver en Mertens, 1995: XX-XLIII.

${ }^{2}$ Véase Holmyard, 1970: 30: «Una asombrosa confusión de magia egipcia, filosofía griega, gnosticismo, neoplatonismo, astrología babilónica, teología cristiana y mitología pagana, juntamente con un lenguaje enigmático que hace que la interpretación de la literatura alquímica sea tan difícil como insegura».

${ }^{3}$ Históricamente, los tres principales objetivos que persiguen los alquimistas son la transmutación de los metales comunes en metales preciosos, la piedra filosofal y el elixir de la eterna juventud.

${ }^{4}$ Algunos de estos pensaban que la correcta elección de la «materia prima» solo se conseguía por inspiración divina o por una especie de gracia especial que otorgaba Dios, en principio, a ciertos elegidos, únicos interpretes de los secretos de la naturaleza.

${ }^{5}$ Para verificar las principales operaciones alquímicas de laboratorio, la artesanía primitiva ya disponía de utensilios adecuados para llevarlas a efectos. Los alquimistas, si acaso, los perfeccionaron. 
(Léxico alfabético de la Crisopea) ${ }^{6}$. En él se puede consultar la terminología empleada por un alquimista para que aquellas personas no iniciadas desconocieran la «materia prima", es decir, los materiales o las sustancias que servirían de base para su operación alquímica y, consecuentemente, no lograsen adentrarse en este mundo privilegiado de unos pocos expertos.

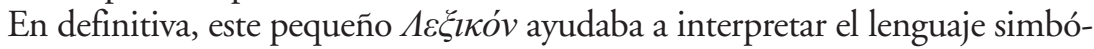
lico de los propios textos alquímicos. El huevo -o alguna de sus partes- como «materia prima» se cita, de una manera particular, en once ocasiones? ${ }^{7}$ Por orden alfabético y con su traducción son:

Con la A:

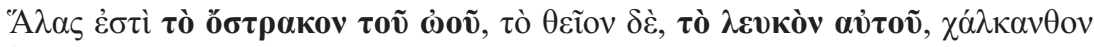

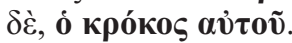

"Sal es la cáscara de huevo; el azufre, lo blanco de él'; y el vitriol", su yema".

${ }^{6}$ Este $\Lambda \varepsilon \xi$ ı́óv se encuentra en el manuscrito Marcianus graecus 299 (= M: folios 131r-136v): véase Mertens, 1995: XXVII. Este manuscrito, copiado sobre pergamino, es considerado por la crítica especializada el más antiguo y hermoso de los manuscritos alquímicos.

${ }^{7}$ Para el texto griego se ha empleado la edición de la Collection des Anciens Alchimistes (CAG): véanse Berthelot - Ruelle, 1967: 4-17.

${ }^{8}$ "Lo blanco de un huevo", es decir, la clara, se emplea también como un componente más en los repertorios de remedios, fórmulas o recetas alquímicas: véase Halleux, 2002: del Papiro X de

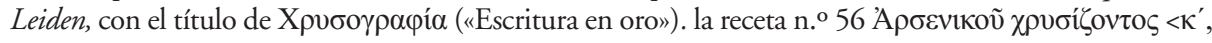

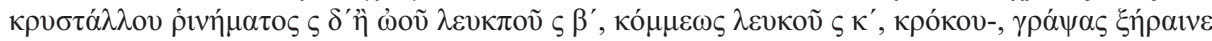

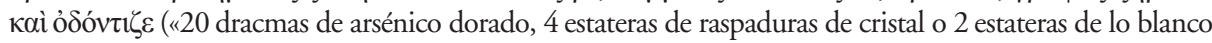
de un huevo, 20 estateras de goma blanca, azafrán; después de escribir, séquelo y púlalo con un diente»)

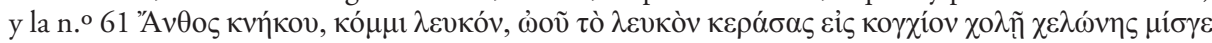

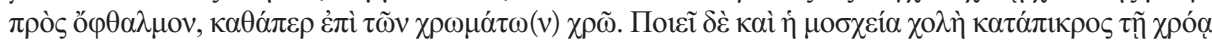
(«Flor de azafranillo, goma blanca, lo blanco de un huevo, mézclelo en una concha pequeña y añada a la mezcla bilis de tortuga, a ojo, como se hace para los colores. También la bilis de ternera, especial-

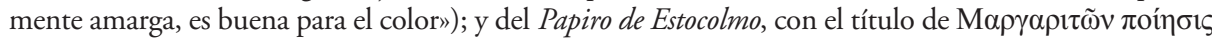

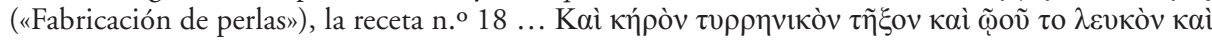

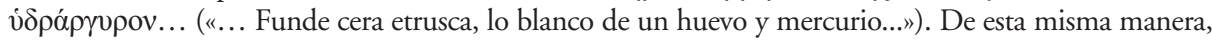

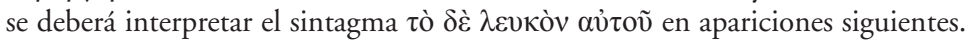

${ }^{9}$ Vitriolo es el nombre antiguo del sulfato de cobre. Vitriolo viene de la palabra latina vitriolum, contracción de vitri oleum, literalmente "aceite de vidrio». Según la tradición alquímica, el término vitriolum es un acrónimo formado por las iniciales del lema Visita Interiora Terrae Rectificandoque Invenies Occultum Lapidem Veram Medicinam («visita el interior de la tierra y rectificando hallarás la piedra oculta, la medicina verdadera») y utilizado por la masonería para presidir sus cámaras o gabinetes de reflexión, donde el neófito que va a ser iniciado deberá permanecer un lapso de tiempo indefinido, antes de entrar en un templo masónico. Este lema fue dado a conocer, por primera vez, por el alquímico Daniel Stolcius en su libro de emblemas Viridarium Chymicum, Frankfurt, 1624. Por otro lado, véase la discusión sobre

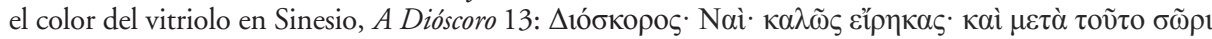

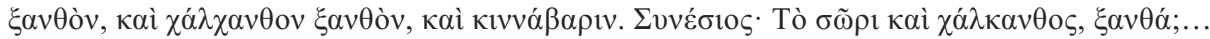
(«Dióscoro.- Sí, bien has hablado. Y, a continuación, melanterita o-melanteria- amarilla, vitriolo amarillo y cinabrio. Sinesio.- ¿Amarillos la melanterita - melanteria- y el vitriolo?...»). 
Con la E:

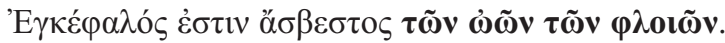

"Encéfalo es cal viva de las membranas de los huevos".

Con la $\Theta$ :

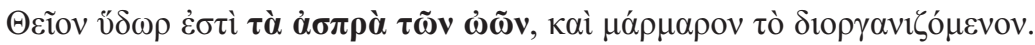
"Agua de azufre es lo blanco de los huevos y lo que se pasa por el 'diorganismo' (especie de alambique) es mármol”.

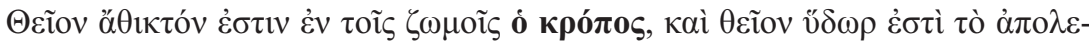

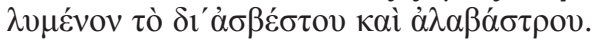

"Azufre sin impurezas es la yema y el agua de azufre es lo que se desprende a partir de la cal viva y el alabastro".

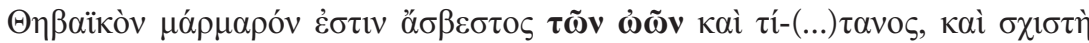

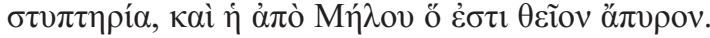

"Mármol tebano es cal viva de los huevos, cal, alumbre laminado y el procedente de Melos que es azufre sin quemar".

Con la K:

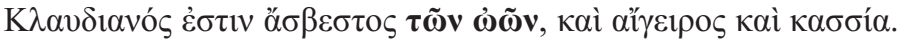

"Claudiano ${ }^{10}$ es cal viva de los huevos, chopo y casia".

Con la $\Sigma$ :

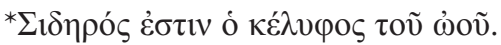

"Hierro es la cáscara del huevo".

Con la T:

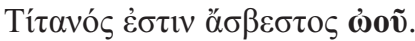

"Cal es cal viva del huevo".

Con la X:

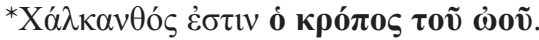

"Vitriol es la yema del huevo".

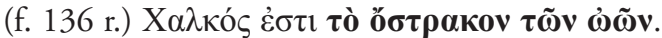

"Cobre es la cáscara de los huevos"

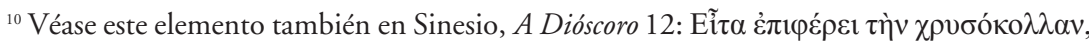

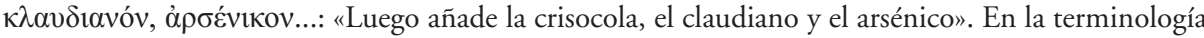
mística de la alquimia, el claudiano es un elemento que se compone de diversos integrantes (aleación de plomo y estaño): cf. Garzya, 1989: 807, n. 14. 


\section{Con la $\Omega$ :}

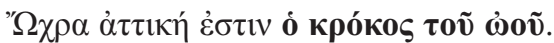

"Ocre ática es la yema del huevo".

Según esto y teniendo este léxico como libro «de mano», un alquimista, en vez de citar como componentes de su operación alquímica, la sal, el azufre o el cobre, los podía sustituir por las partes de un huevo, como se ha podido ver en las referencias de arriba. Es decir, un iniciado, una persona sin un léxico de este tipo o sin unos conocimientos previos, sería incapaz de realizar cualquier operación alquímica. Se hace, por tanto, necesario un «manual de cocina»-permítase esta comparación-, como este, para poder «cocinar».

Además del citado Léxico alfabético de la Crisopea, la $C A G$ recoge otros dos textos de los manuscritos alquímicos ${ }^{11}$, que tienen como protagonista, en exclusiva,

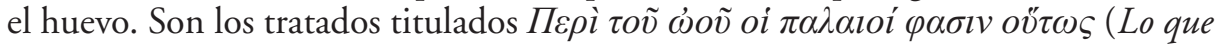

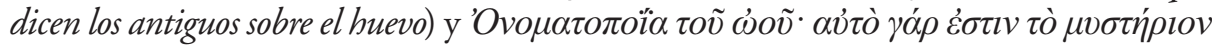
$\tau \tilde{\eta} \varsigma \tau \varepsilon_{\chi} \chi v \eta \varsigma$ (La nomenclatura del huevo: este es el misterio del arte).

En estos textos, de los que se ofrece también una traducción, se encierra una nomenclatura, como se ha comentado, totalmente simbólica ${ }^{12}$. En el primero, las partes de un huevo se sustituyen por minerales, líquidos, fermentos..., en la línea

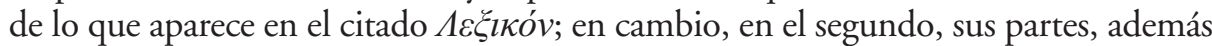
de aludir a diversos materiales y sustancias, se identifican con los cuatro elementos de la naturaleza: el fuego, el aire, el agua y la tierra ${ }^{13}$.

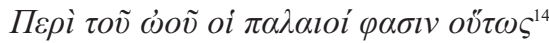

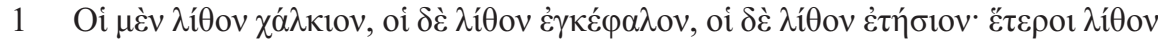

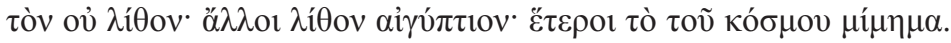

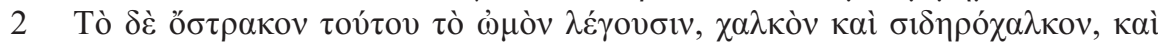
$\mu о \lambda v \beta \delta o ́ \chi \alpha \lambda \kappa o v, \kappa \alpha i ̀ ~ \sigma \omega ́ \mu \alpha \tau \alpha \sigma \tau \varepsilon \rho \varepsilon \alpha ́$.

${ }^{11}$ Berthelot - Ruelle, 1967: 18-21.

${ }^{12}$ Este tipo de terminología metafórica y, en ciertos textos, encriptada aparece ya en las Memorias auténticas de Zósimo de Panópolis (véase Mertens, 1995), por lo que cabría interpretar que su empleo era habitual en los primeros textos de la alquimia.

${ }^{13}$ Los alquimistas retoman la vieja teoría griega de los cuatro elementos de la naturaleza, en espe-

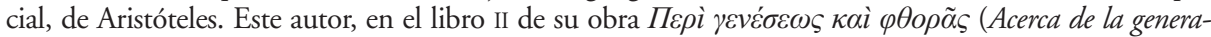
ción y la corrupción), proponía que el universo estaba formado por la combinación de los cuatro elementos presocráticos de la teoría pluralista de Empédocles: la tierra, el agua, el aire y el fuego. En este sentido, postulaba la existencia de una materia prima que subyace a los cambios de estos elementos, introduciendo la idea de la trasmutación entre sí de estos mediante el intercambio de algunas de sus propiedades primarias que los caracterizan: lo caliente y lo seco (cualidades del fuego), lo caliente y lo húmedo (cualidades del aire), lo frío y lo húmedo (cualidades del agua), y lo frío y lo seco (cualidades de la tierra); es decir, cada uno de los cuatro elementos posee dos cualidades, cada una de las cuales es compartida, a su vez, por otro.

${ }^{14}$ Berthelot - Ruelle, 1967: 18-20 (folios 106v-107r del manuscrito M). 


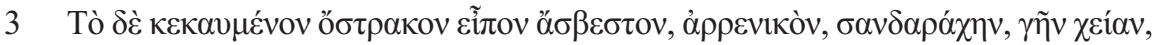

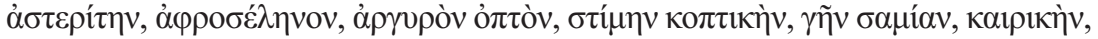

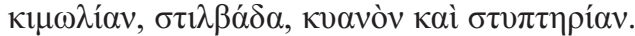

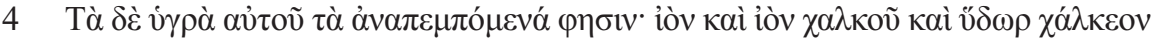

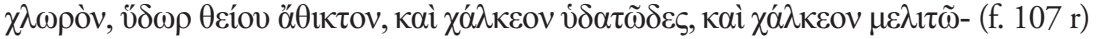

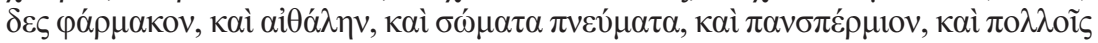

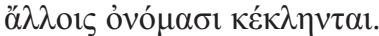

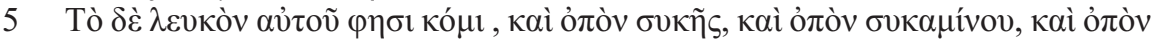
$\tau \imath \theta v \mu \alpha ́ \lambda o v$.

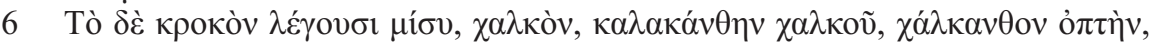

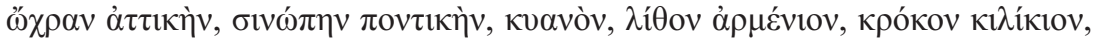

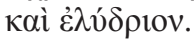

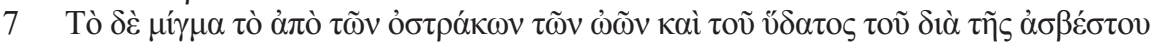

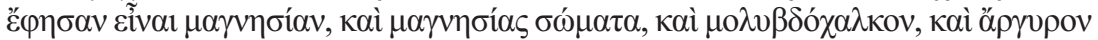

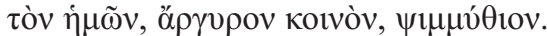

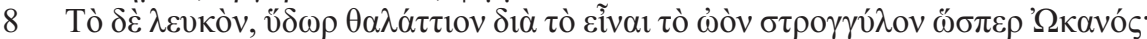

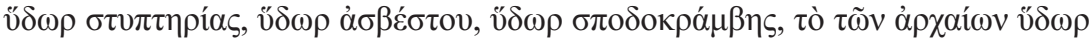

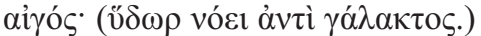

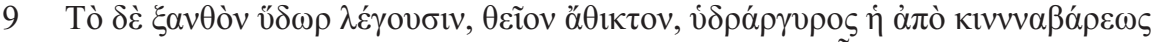

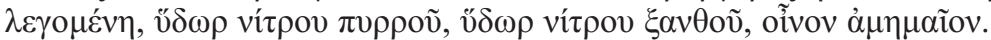

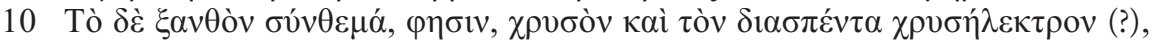

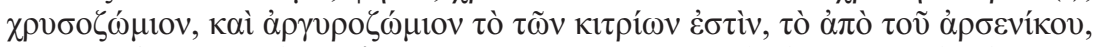

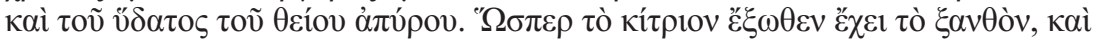

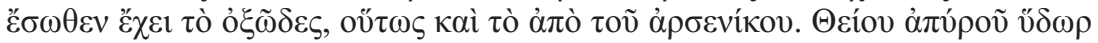

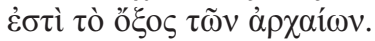

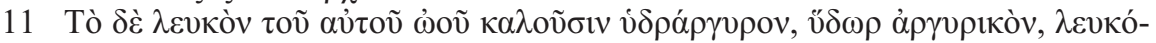

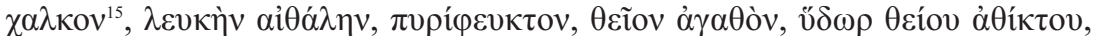

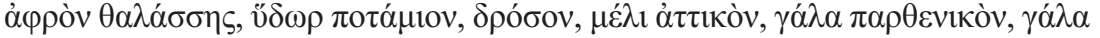

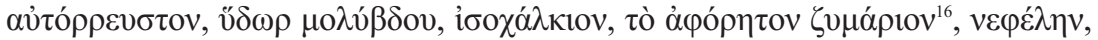

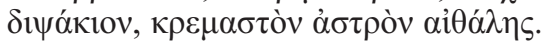

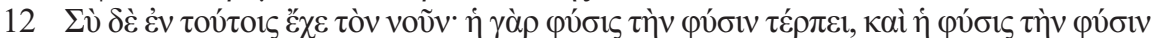

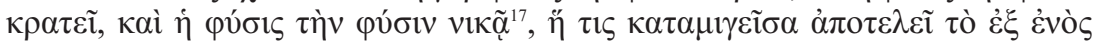

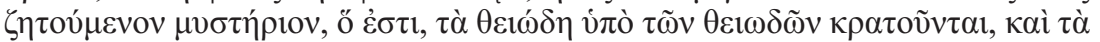

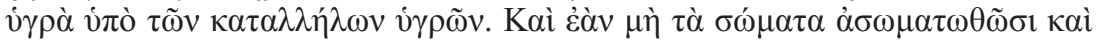

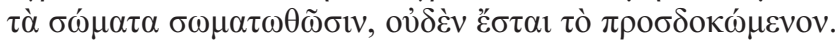

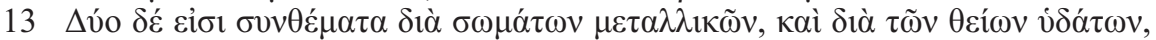

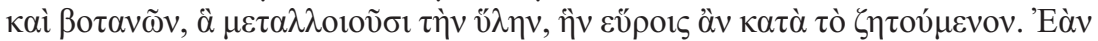

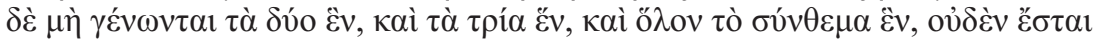

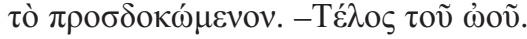

\footnotetext{
${ }^{15}$ Posible hápax. No está en los diccionarios de uso habitual.

${ }^{16}$ Otro posible hápax. Como en el caso anterior, tampoco se encuentra en los diccionarios de uso habitual.

${ }^{17}$ Sintagmas recurrentes en diferentes textos de los antiguos alquimistas griegos, como, por ejemplo, cuando se habla del Uróboro, la serpiente que se muerde la cola: cf. Fernández García, 2017-2018: 75 (párrafo n. ${ }^{\circ}$ 3).
} 


\section{"Lo que dicen los antiguos sobre el huevo»}

1 Unos lo ${ }^{18}$ llamaron piedra de cobre; otros, piedra encéfalo ${ }^{19}$; otros, piedra etesia ${ }^{20}$; otros, piedra no piedra ${ }^{21}$; otros, piedra egipcia ${ }^{22}$; y otros, la imagen del universo ${ }^{23}$.

2 Dicen que la cáscara, su parte que no se cuece, es cobre; aleación de hierro y cobre; aleación de plomo y cobre; y cuerpos sólidos.

3 Dijeron que la cáscara calcinada es cal viva, arsénico, rejalgar ${ }^{24}$, tierra de Quíos, asterita $^{25}$, selenita, plata cocida, antimonio de Egipto, tierra de Samos, tierra apropiada, cimolita, tierra brillante, azurita y alumbre.

${ }^{18}$ Se refiere al huevo.

${ }^{19}$ En Memorias auténticas de Zósimo de Panópolis: n. ${ }^{\circ}$ XIII (Mertens, 1995: 48) se relaciona

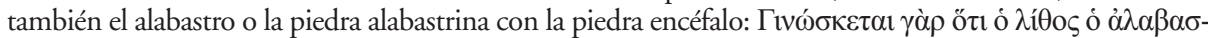

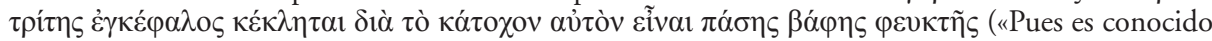
que la piedra de alabastro se llamó encéfalo por actuar como fijador de cualquier tinte fugaz»). En este

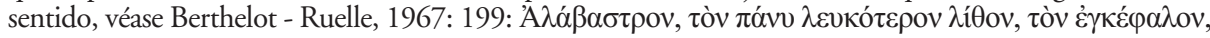

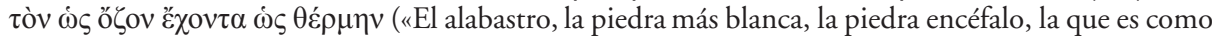

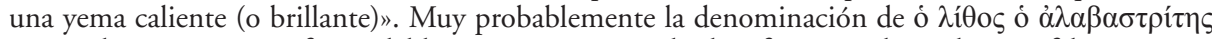
es una designación metafórica del huevo. En este sentido, la referencia a la piedra encéfalo estaría en entender la cáscara que cubre a la yema del huevo como el cráneo que cubre el cerebro.

${ }^{20} \mathrm{La}$ etesia es una piedra especial para hacer morteros, como atestigua, por ejemplo, Plinio HNXXXVI (157): Auctoribus curae fuere lapides mortariorum quoque, nec medicinalium tantum aut ad pigmenta pertinentium. Etesium lapidem in iis praetulere ceteris, mox Thebaicum... («Los autores tuvieron cuidado para hacer morteros de piedras, y no solo para las drogas o los colores. Para ello, el primero que está en la clasificación es la piedra etesia; en segundo lugar, la piedra tebaica...»).

${ }^{21}$ Expresión antitética que está incluida también entre las que aparecen en las Memorias

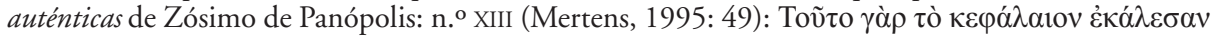

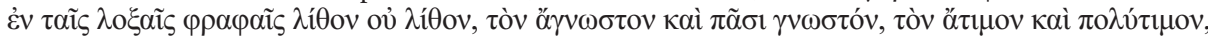

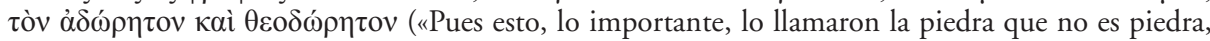
lo desconocido y lo conocido por todos, lo deshonroso y lo muy honroso, y lo que no reporta beneficio y lo que concede la divinidad»). Estas expresiones contrapuestas reflejan que el huevo, que es algo insignificante para el común de los mortales, es extremadamente relevante para los alquimistas que saben cómo trabajarlo.

${ }^{22}$ Puede que se refiera a la piedra caliza, caracterizada por su color claro, blanquecino o gris y que servía para preparar morteros, como la piedra estesia citada anteriormente. Se daba en las canteras de piedra de las colinas de Muqattum, cerca de Menfis.

${ }^{23}$ Cf. Jung, 2016: 325.

${ }^{24}$ Habitualmente, en la farmacopea antigua se denomina con el término «sandáraca» una resina de color amarillo, procedente de algunas coníferas (véase, en este sentido, por ejemplo: Dioscó-

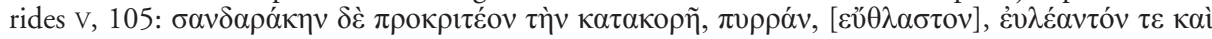

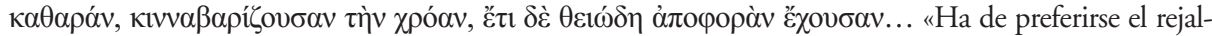
gar de color intenso, rojo, [desmenuzable], fácil de majar y puro, el que se parece al cinabrio en el color y tienen además un olor semejante al del azufre...») [Dioscórides Interactivo: http://dioscorides.usal.es/p2. php?numero=891]; o Plinio XI, 7: Praeter haec convehitur erithace, quam aliqui sandaracam, alii cerinthum vocant... ("Además de estas cosas acarrean la erítaca, que unos llaman sandáraca y otros cerinto»). Con este mismo término griego se conoce un mineral formado por sulfuro de arsénico, de color rojo, aspecto resinoso y muy venenoso que se emplea, sobre todo, en pirotecnia y marroquinería: el «rejalgar». Por el contexto, se desprende que, en este caso, se refiere a este mineral.

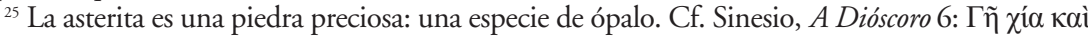

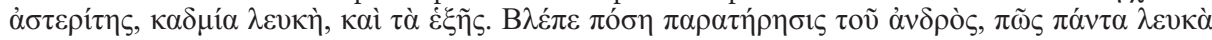

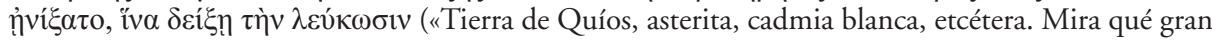
perspicacia la de este hombre, cómo apuntó a lo blanco para mostrar el emblanquecimiento»). 
4 Las partes líquidas del huevo dicen que son las que se elevan: herrumbre; herrumbre de cobre; agua verde cobriza; agua de azufre sin impurezas; preparación de cobre con aspecto acuoso y preparación de cobre con aspecto de miel; vapor sublimado; cuerpos volátiles; y semilla universal; y también reciben muchas otras denominaciones.

5 Lo blanco del huevo dicen que es goma, jugo de higo, jugo de morera y jugo de titímalo.

6 La yema del huevo comentan que es mineral de cobre, cobre, sulfuro de cobre, vitriolo cocido, ocre ática, tierra sinópica ${ }^{26}$ del Ponto, lapislázuli, piedra de Armenia, azafrán de Cilicia y celidonia.

$7 \quad$ La mezcla de las cáscaras de los huevos y del agua que se extrae de la cal viva han dicho que es magnesia, cuerpos de magnesia, aleación de plomo y cobre, nuestra plata, plata común y cerusa.

8 Dicen $^{27}$ que lo blanco es agua marina porque el huevo es redondo como Océano; agua de alumbre, agua de cal viva, agua de ceniza de col, agua de cabra de los antiguos: (ten presente que es agua, en vez de leche).

9 Cuentan que lo amarillo ${ }^{28}$ es agua de azufre sin impurezas, mercurio del que se dice que sale del cinabrio, agua de natrón rojo, agua de natrón amarillo, vino amíneo ${ }^{29}$.

10 Dicen que la operación amarilla es oro y electro dorado putrefacto; fermento de oro; y fermento de plata, el que se saca de los limones, el que procede del arsénico y el que se saca del agua del azufre sin quemar. Como el limón tiene por fuera lo amarillo y por dentro lo ácido, igual le pasa a lo que procede del arsénico. El agua de azufre sin quemar es el vinagre de los antiguos.

11 Lo blanco del huevo lo llaman mercurio, agua de plata, cobre blanco ${ }^{30}$, vapor sublimado blanco, volátil, azufre de buena calidad, agua de azufre sin impurezas, espuma marina, agua de río, rocío, miel ática, leche de doncella, leche que sale por sí sola ${ }^{31}$,

${ }^{26}$ También conocida por rúbrica sinópica. Su nombre lo toma de Sinope, ciudad situada en la región de Capadocia (Asia Menor). La tierra o rúbrica sinópica se caracteriza, evidentemente, por su color rojo. Su empleo era conocido en la Antigüedad: véase, por ejemplo, Estrabón, Geografía III,

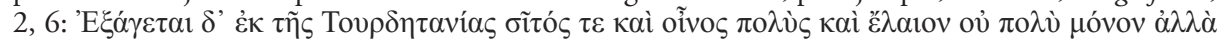

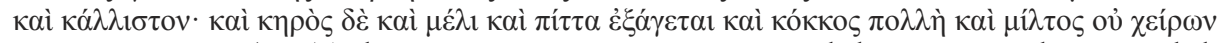
$\tau \tilde{\eta} \varsigma \Sigma(v \omega \pi \imath \kappa \tilde{\eta} \varsigma \gamma \tilde{\eta} \varsigma$ ( De Turdetania se exporta trigo y vino en cantidad, y aceite no solo en cantidad, sino también de la mejor calidad. Se exporta asimismo cera, miel y pez, mucha y un bermellón no inferior a la tierra sinópica»).

${ }^{27}$ Debe entenderse aquí un «verbo de lengua».

${ }^{28}$ «Lo amarillo» del huevo es, en este caso, su yema. Así también habrá de interpretarse en sucesivas apariciones.

${ }^{29}$ Es un vino italiano muy prestigiado desde antiguo: véase Columela, Res rustica III, 9, 2-3: Unam etiam praecoquem vitem nobis ante hoc tempus incognitam Graeca consuetudine Dracontion vocitari comperimus, quae fecunditate iucunditateve Arcelacae Basilicaeque et Bituricae compari possit, generositate vini Amineae ("También hemos tenido noticia de una particular vid temprana, antes de ahora desconocida para nosotros, que recibe el nombre de dracontion a la manera griega y que podría compararse a la arcelaca o al balisca, y a la biturica por su fecundidad o disfrute, y a la amínea por la gran calidad

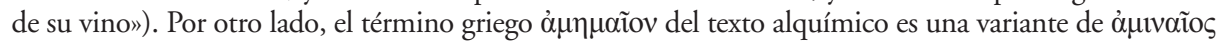
o $\alpha \mu \mu t v \alpha i ̃ o s$, por lo que podría tratarse de un posible caso de vacilación iotácica.

${ }^{30}$ Probablemente, hace referencia al cuproniquel, que se usaba en la antigüedad para modificar y alterar el contenido de las monedas de plata.

${ }^{31}$ Se debe referir a la leche que se pierde durante la lactancia cuando el pecho gotea. 
agua de plomo, herrumbre de cobre, fermento no empleado con anterioridad, nube y astro suspendido de vapor sublimado.

12 Pon tu entendimiento en estas cosas. Pues la naturaleza goza de la naturaleza, la naturaleza domina a la naturaleza; la naturaleza vence a la naturaleza; la que una vez mezclada lleva a término el misterio buscado a partir de uno solo ${ }^{32}$; es decir, los sulfuros son dominados por los sulfuros y los líquidos, por los líquidos correspondientes. Y tanto si los cuerpos no llegaran a ser volatilizados, como si llegaran, no se cumplirá lo esperado.

13 Son dos las operaciones que se dan a partir de cuerpos metálicos, de aguas divinas y plantas, que harían cambiar la materia que pudieras encontrar, según lo que estés buscando. Si dos cuerpos no llegaran a hacerse uno, si tres cuerpos no lograran convertirse en uno, y si toda la operación completa no se hiciera de una única manera, no se cumplirá lo esperado. - Fin del huevo.»

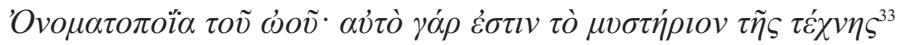

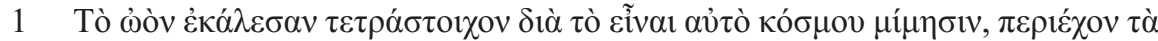

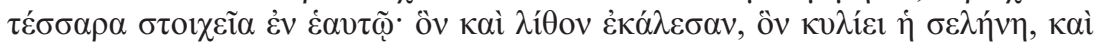

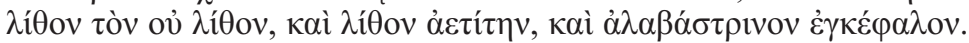

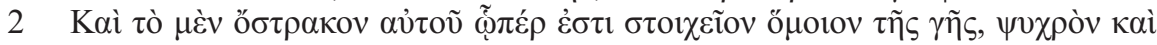

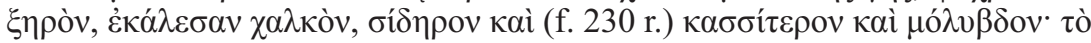

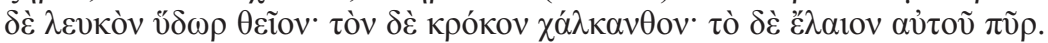

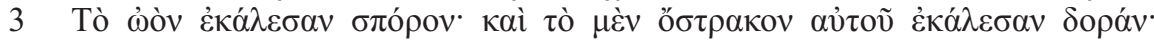

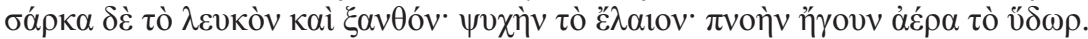

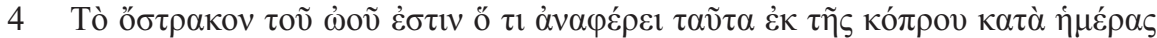

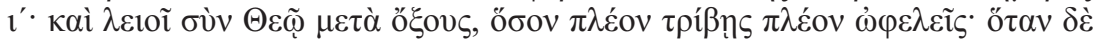

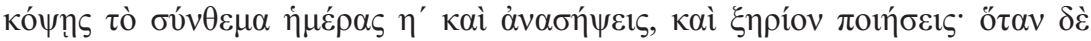

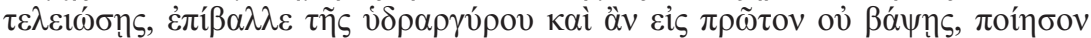

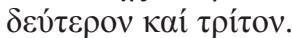

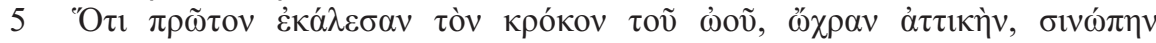

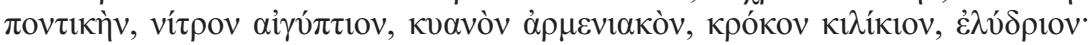

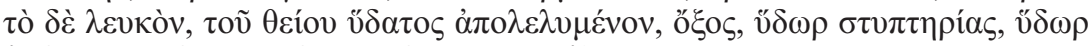

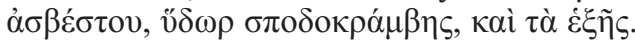

\section{«La nomenclatura del huevo: este es el misterio del arte»}

1 Comentaron que el huevo está formado por cuatro elementos, porque es él la imagen del mundo y contiene en sí mismo los cuatro elementos. Dijeron, además, que es la piedra que la luna hace girar, la piedra no piedra, la piedra del águila ${ }^{34} \mathrm{y}$ el cerebro alabastrino ${ }^{35}$.

${ }^{32}$ Parece que se refiere a la utilización de un único elemento.

${ }^{33}$ Berthelot - Ruelle, 1967: 20-21 (folios 229r-230r del manuscrito M).

${ }^{34}$ También llamada «etites». En minerología, esta piedra es una concreción de óxido de hierro en bolas informe, compuestas de varias capa concéntricas de color amarillo y pardo rojizo. En la Antigüedad se creía que las águilas llevaban esta piedra a sus nidos para facilitar la postura, de ahí la raíz de su nombre. Véase, por ejemplo, Plinio NHX (12): lapis aëtites [...], praegnans intus alio, cum quatias, velut 
2 Su cáscara es un elemento semejante a la tierra, frío y seco, al que llamaron cobre, hierro, estaño y plomo; lo blanco es agua divina; la yema es vitriol ${ }^{36}$; y su aceite es fuego.

3 Interpretaron que el huevo es la semilla; que su cáscara, la piel; que lo blanco y lo amarillo, la carne; que el aceite, el alma; y que el agua, soplo, es decir, aire.

4 La cáscara del huevo es lo que soporta esas cosas que proceden del excremento durante diez días. Descomponlo con vinagre, con ayuda de Dios, y cuanto más lo disuelvas, más te saldrá. Cuando hayas machacado la composición durante ocho días y la hayas hecho fermentar, obtendrás polvo seco. Cuando hayas terminado, añade mercurio $y$, si no consigues la tintura la primera vez, hazlo una segunda y una tercera vez.

5 Porque, al principio, llamaron a la yema del huevo: ocre ática, tierra sinópica ${ }^{37}$ del Ponto, natrón de Egipto ${ }^{38}$, azurita de Armenia, azafrán ${ }^{39}$ de Cilicia, celidonia; y a lo blanco del huevo, desligado con agua de azufre: vinagre, agua de alumbre, agua de cal viva, agua de ceniza de col, etc.

Un apunte más para finalizar este trabajo. Entre los pasajes más interesantes de los citados aquí, está el siguiente de La nomenclatura del huevo: este es el misterio

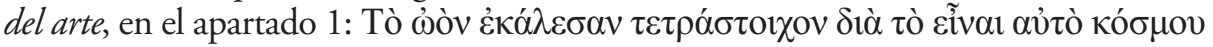

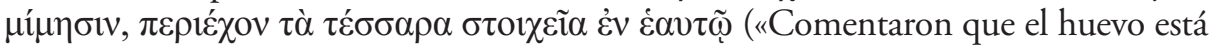
formado por cuatro elementos, porque es él la imagen del mundo y contiene en sí mismo los cuatro elementos»).

¿Por qué es un pasaje relevante? Al comienzo de este artículo ya se indicó que los textos alquímicos son complicados por su simbolismo, y por la complejidad y la incomprensibilidad de su terminología y de las operaciones alquímicas que

\footnotetext{
in utero sonante («la piedra etites [...], está preñada, de manera que, cuando la agitas, suena dentro otra como en el interior de un vientre»); NH XXX (130): Lapis aëtites in aquilae repertus nido custodit partus contra omnes abortuum insidias... ("La piedra "etites" que se puede encontrar en un nido de un águila protege el parto de posibles riesgos de aborto...»); y NHXXXVI (149-151): Aëtitae lapides ex argumento nominis magnam famam habent. reperiuntur in nidis aquilarum... ("Las piedras "etites" tienen gran fama por el tema de su nombre y porque se encuentran en los nidos de las águilas...»). O Dioscórides V, 118:

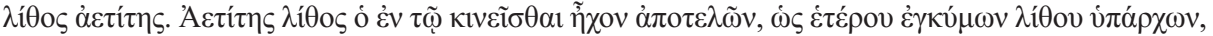

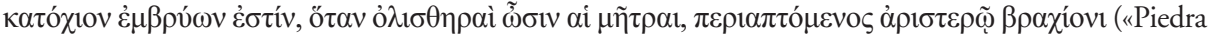
del águila. Es una piedra que al moverla produce eco como si estuviera preñada de otra piedra; retiene los embriones cuando la matriz es resbaladiza, si se lleva atada como amuleto en el brazo izquierdo») [Dioscórides Interactivo: http://dioscorides.usal.es/p2.php?numero=930].

${ }^{35}$ Véase n. 19.

${ }^{36}$ Véase n. 9.

${ }^{37}$ Véase n. 26.

${ }^{38}$ El natrón es una sal compuesta de carbonato sódico, bicarbonato sódico, sulfato sódico y cloruro sódico, que en Egipto se encontraba en estado natural. Los egipcios la emplearon para la momificación, porque deshidrataba la carne, detenía la descomposición y secaba los tejidos, actuando también como agente antibacteriano, por lo que tenía a denominación de "sal divina». Sería el mismo principio del proceso de salazón del pescado. y "azafrán”.

${ }^{39}$ En este mismo pasaje el término крóкоv se utiliza con dos significados diferentes: "yema”
} 
describen; y se convierten, en muchas ocasiones, en textos alegóricos que pueden causar numerosos errores de interpretación. Uno de estos es confundir el huevo como «materia prima» y el «huevo filosófico» (se denomina de esta manera a uno de los instrumentos necesarios para que la operación alquímica saliera exitosa).

El concepto del huevo como «imagen del mundo que contiene en sí mismo los cuatro elementos» de la tradición aristotélica ${ }^{40}$ es el punto de partida, para que la literatura alquímica posterior a la griega genere el concepto de «huevo filosófico» ${ }^{41}$.

¿Por qué la denominación de «huevo filosófico»? En primer lugar, habría que indicar que numerosas culturas y civilizaciones antiguas, separadas y aparentemente sin ninguna relación, inciden en las metáforas sobre elementos de ontología cósmica o metafísica mediante un huevo: este cuerpo redondo u ovalado es un símbolo universal asimilado a la creación y a la renovación constante de la naturaleza. En este sentido, un huevo entraría dentro de esas imágenes arquetípicas compartidas por las tradiciones religiosas y folclóricas de los diferentes pueblos, y que encuentran un sitio relevante en la historia de la literatura alquímica.

Por lo general, en las mitologías antiguas, un huevo es producido o manufacturado por un dios o una diosa. Por citar una referencia conocida, en la mitología griega se da el caso del nacimiento de los Dioscuros, los gemelos Cástor y Pólux, fruto de los amores de Zeus, metamorfoseado en cisne, y Leda, a partir de un huevo.

${ }^{40}$ Véase n. 13.

${ }^{41}$ En la traducción al inglés que Waite hace del texto más antiguo, según la crítica especializada, de la alquimia europea y traducido del árabe, Turba Philosophorum, se dice lo siguiente: «An egg is an illustration, for therein four things are conjoined; the visible cortex or shell represents the earth, and the albumen, or white part, is the water.* But a very thin inner cortex is joined to the outer cortex, representing, as I have signified to you, the separating medium between earth and water, namely, that air which divides the earth from the water. The yolk also of the egg represents fire; the cortex which contains the yolk corresponds to that other air which separates the water from the fire. But they are both one and the same air, namely, that which separates things frigid, the earth from the water, and that which separates the water from the fire. But the lower air is thicker than the upper air, and the upper air is more rare and subtle, being nearer to the fire than the lower air In the egg, therefore, are four things earth, water, air, and fire. But the point of the Sun, these four excepted, is in the centre of the yolk, and this is the chicken. Consequently, all philosophers in this most excellent art have described the egg as an example, which same thing they have set over their work» (1896: 11: «Discurso IV»). En la nota a este texto $\left(^{*}\right)$, Waite explica lo siguiente: «The allegory of the philosophical egg can be traced to the Greek alchemists. A short treatise is still extant under this title, and another on the Nomenclature of the Egg, which is described as the Mystery of the Art. It is composed of four elements, because it is the image of the world. It is the stone which is not a stone, the stone of copper, the Armenian stone, \&c. The shell is likened to the earth, being cold and dry ; it has been named copper, iron, tin, lead. The white of the egg is divine water, water of the sea, water of alum, \&c. The yolk is copperas, native sulphur, mercury, \&c. The oily part (? the chicken) is fire. But the egg, symbolical-as it is, is sometimes itself described symbolically, after the similitude of a seed ; the shell is likened to the skin which covers the seed; the white and the yolk are the flesh, and the watery part is the breath, or air». La Turba Philosophorum figura entre las autoridades más antiguas de la alquimia latina (Jung, 2016: 185 [234]). 
De esta manera y desde antiguo, los alquimistas fueron incorporando progresivamente fábulas y mitos clásicos, ciertos episodios históricos y un buen número de figuras alegóricas, símbolos y emblemas —o «jeroglíficos»— procedentes del ámbito moral y religioso, en un "complejo sistema de correspondencias múltiples», de notable riqueza expresiva y capacidad de sugerencia, pero cuya comprensión implicaba una ardua labor de iniciación ${ }^{42}$.

A todo esto, habría que añadir que en la gnoseología alquímica, previa al pensamiento científico, se creía que los minerales se gestaban en un vientre telúrico en el centro de la tierra ${ }^{43}$ : como una gallina que incuba sus huevos, el alquimista incuba, a su vez, los materiales y las sustancias en el «huevo filosófico» dentro del atanor u horno, herméticamente cerrado, hasta que logra con éxito sus reacciones o transformaciones, cuyas fases son descritas, de una forma más o menos alegórica, en todos los libros alquímicos, en especial, de la Edad Media y del Renacimiento ${ }^{44}$.

Hay que tener en cuenta, además, que el objetivo de la alquimia es replicar e imitar el proceso de la creación. En consecuencia, el alquimista imita el proceso de una gestación, encerrando sus materias en el «huevo filosófico», que contiene en sí todo lo necesario para que la «materia prima» evolucione sin añadir ni quitar nada más. Si todo ha sido dispuesto de manera satisfactoria, se obtiene como alumbramiento final lo que textos alquímicos denominan, según los casos, la Piedra Filosofal, el Elixir de la Larga Vida, el Disolvente Universal...

En efecto, entre los utensilios y aparatos que emplearon los alquimistas para sus diferentes operaciones (calcinación, fusión, fermentación, cristalización, destilación, sublimación...), tenían absoluto protagonismo en el laboratorio alquímico, sobre los demás, el alambique ${ }^{45}$ y el llamado «huevo filosófico».

$\mathrm{El}$ «huevo filosófico» ha recibido en los textos alquímicos diferentes nombres, escogidos con la intención de ocultar a los profanos no solo su verdadero destino, sino también su composición. Así, se pueden encontrar denominaciones como: "huevo alquímico», «huevo cósmico» o incluso "gran vaso de Hermes» ${ }^{46}$.

Pero, ¿qué es en sí el «huevo filosófico»? Este objeto es una especie de vasija, matraz o retorta de forma esférica y ovoide ${ }^{47}$, hecha de un vidrio transparente, para permitir que el alquimista pudiera observar todas las transformaciones que se iban

${ }^{42}$ Véase Klossowski de Rola, 1988: 21.

${ }^{43}$ Esta idea está ampliamente desarrollada por Eliade, 1983.

${ }^{44}$ En especial, a partir del descubrimiento en 1419 de los Jeroglificos del autor griego tardío Horopalo. Este autor realiza comentarios en los que expone la relación alegórica entre el jeroglífico y su significado, mezclando fantasía y realidad, método que sirvió a los escritores de literatura alquímica del Renacimiento, sobre todo, para escribir numerosos libros de emblemas.

${ }^{45}$ Para este utensilio alquímico, véase nuestro trabajo: Fernández García, 2014.

${ }^{46}$ Tiene también esta denominación por utilizar el sello de Hermes para cerrar «herméticamente» el recipiente -horno o atanor- que lo contiene.

${ }^{47}$ Para imitar el "cosmos esférico», interpretación del cosmos ya propuesta por la mayoría de los pensadores griegos. 
produciendo en su interior; y de un grosor suficiente, para poder resistir tanto las altas temperaturas que se daban en él como las grandes presiones que se generaban en su interior. Se situaba en la parte central del atanor u horno alquímico.

La preparación y formación del «huevo filosófico» es larga y puede durar meses y años, y, en ocasiones, puede resultar inútil. El alquimista tiene que poner un especial cuidado y atención, ya que cualquier error puede dar al traste con una labor de años. Su base de observación serán los cambios de color y apariencia de la mezcla en el interior de este recipiente: si el proceso va progresando de manera satisfactoria, el contenido del «huevo filosófico» irá adquiriendo, con gradaciones lentas, diferentes colores ${ }^{48}$.

Con lo anteriormente dicho, el paso a una alquimia esotérica o mística estaba dado ${ }^{49}$. Si en el «huevo filosófico» se produce una transmutación de materia; en el ser humano, en su interior, se produce una transmutación espiritual ${ }^{50}$ : supone un camino que permite al hombre llegar al conocimiento de su naturaleza inmortal, buscándose a sí mismo y con la misión de desentrañar los misterios de la vida. En esta alquimia esotérica o mística el «huevo filosófico» es el símbolo alquímico de la totalidad donde se forma el «Hermafrodita» ${ }^{51}$ y el éxito del proceso alquímico se llama la "Gran Obra»"

Para finalizar, es necesario recalcar, por tanto, la importancia del pasaje indicado en el que el huevo es la «imagen del mundo que contiene en sí mismo los cuatro elementos». Su simbolismo ha servido, con posterioridad, para inspirar a muchas mentes creadoras e imaginativas que en sus tratados alquímicos podían escribir «algo» significando una cosa, cuando significaba, sin embargo, otra cosa distinta.

\footnotetext{
${ }^{48}$ Fase representada en los grabados antiguos con la figura de un pavo real con la cola desplegada y llena de colores.

${ }^{49}$ En la alquimia esotérica, a los mitos y leyendas del mundo grecorromano se le añaden expresiones y simbolismos de las religiones monoteístas, en especial, de la cristiana y musulmana; cuestiones del zodiaco, de la magia...

${ }^{50}$ Esto es así, puesto que los alquimistas creen que todos los cuerpos, incluidos los minerales, están constituidos por una materia y un espíritu o alma universal.

${ }^{51} \mathrm{El}$ «Hermafodita» -Rebis o Andrógino, según los textos alquímicos- es otro de los motivos preferidos por los alquimistas esotéricos o místicos, puesto que cualquiera de esos términos expresa en este tipo de alquimia la unión de lo sensual y de lo espiritual. Como ejemplo del empleo de estos tres nombres juntos en un texto alquímico, véase el «Emblema XXXVIII» de La fuga de Atalanta (Maier, 2007: 238-239): Rem geminam REBIS veteres dixere, quod uno/Corpore sit mas haec foeminaque, Androgyna./Natus enim binis in montibus HERMAPHRODITUS/Dicitur, Hermeti quem tulit alma Venus./Ancipitem sexum en spernas, nam tibi Regem/Mas idem, mulierque una eademque dabit («Los antiguos relatos hacen de REBIS un ser doble:/andrógino, macho y hembra en un solo cuerpo./Es, nacido en la montaña doble, HERMAFRODITA,/a quien la nutricia Venus dio nacimiento para Hermes./No le desprecies por su sexo ambiguo: este hombre-mujer un día te dará el rey»).

${ }^{52}$ Otra denominaciones son Ars Magna, Opus Magnum, «Gran Arte»...
} 


\section{REFERENCIAS BIBLIOGRÁFICAS}

Berthelot, M. - Ruelle, C. E. (1888): Collection des Anciens Alchimistes Grecs (CAG), vol. II, París [reimp. Osnabrück, 1967].

Eliade, M. (1983): Herreros y alquimistas, Madrid [2.a ed. en castellano].

Fernández García, A. J. (2014): «Instrumentos alquímicos de María la judía», en MarTínez Fernández, A. - Ortega Villarco, B. - Velasco lópez, H. - Zamora Salamanca, H. (eds.), Agalma. (Ofrenda desde la Filología clásica a Manuel García Teijeiro), Valladolid, Universidad de Valladolid, pp. 1001-1010.

FERNÁNDEZ GARCÍA, A. J. (2017-2018): «Uróboro: la serpiente que se muerde la cola en los textos alquímicos griegos», Fortunatae 28, 69-79 [http://doi.org/10.25145/j.fortunat.2018.28.007].

Garzya, A. (1989): Opere di Sinesio di Cirene. Epistole, Operette, Inni, Turín.

GonZÁlez Hernando, I. (2012): «La piedra de la locura», Revista Digital de Iconografia Medieval 8: 79-88.

Halleux, R. (2002): Les Alchimistes Grecs. t. I: Papyrys de Leyde. Papyrus de Stockholm. Recettes, Les Belles Lettres, París.

Holmyard, E. J. (1970): La prodigiosa historia de la Alquimia, Madrid.

JUNG, C. G. (2016): Mysterium coniunctionis, Obra completa, vol. 14, Madrid [3.a ed. en castellano].

LÓpez PARdo, F. (2002): «Sandáraca, el ámbar de los dioses en las costas de la factoría fenicia de Mogador/Kerné (Marruecos atlántico)», Akros 1: 48-53.

MAIER, M. (2007): La fuga de Atalanta, Girona [Introducción: Joscelyn GodwIN y traducción del inglés: María TABUYO y Agustín López].

Mertens, M. (1995): Les Alchimistes grecs, IV. Zosime de Panopolis. Mémoires autentiques, París.

KLOSSOWsKi de Rola, S. (1988): El Juego Áureo, Madrid.

Sheppard, H. J. (1962): «Egg Symbolism in Alchemy», Ambix 6 (3): 140-148.

Waite, A. E. (1896): The "Turba Philosophorum», Londres. 